\title{
The Design of Stall-Regulated Wind Turbine Blade for a Maximum Annual Energy Output and Minimum Cost of Energy Based on a Specific Wind Statistic
}

\author{
W. Sridech*, T. Chitsomboon \\ School of Mechanical Engineering, Institute of Engineering, Suranaree University of Technology, \\ Nakhonratchasima Province, Thailand

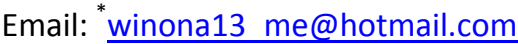

Received April 2014

\section{Abstract}

The design of a stall-regulated wind turbine to achieve a maximum annual energy output is still a formidable task for engineers. The design could be carried out using an average wind speed together with a standard statistical distribution such as a Weibull with $k=2.0$. In this study a more elaborated design will be attempted by also considering the statistical bias as a design criterion. The wind data used in this study were collected from three areas of the Lamtakong weather station in Nakhonratchasima Provice, the Khaokoh weather station in Phetchaboon and the Sirindhorn dam weather station in Ubonratchathani, Thailand. The objective is to design a best aerodynamic configurations for the blade (chord, twist and pitch) using the same airfoil as that of NREL Phase VI wind turbine. Such design is carried out at a design wind speed point. Wind turbine blades were optimized for both maximum annual energy production and minimum cost of energy using a method that take into account aerodynamic and structural considerations. The work will be carried out by the program "SuWiTStat" which was developed by the authors and based on BEM Theory (Blade Element Momentum). Another side issue is the credibility of the Weibull statistic in representing the real wind measurement. This study uses a regression analysis to determine this issue.

\section{Keywords}

Component, Wind Turbine Blade Design, Annual Power Yield, Local Wind Statistic, Cost of Energy

\section{Introduction}

To optimize the performance of fixed speed or stall-regulated wind turbine is a complex procedure according to the several trade-off decisions. This type of wind turbine is mostly a small and medium size that is suitable for a

*Corresponding author.

How to cite this paper: Sridech, W. and Chitsomboon, T. (2014) The Design of Stall-Regulated Wind Turbine Blade for a Maximum Annual Energy Output and Minimum Cost of Energy Based on a Specific Wind Statistic. Journal of Power and Energy Engineering, 2, 10-21. http://dx.doi.org/10.4236/ipee.2014.26002 
household utilization in the remote areas. The initial capital cost of investment is likely low due to the unnecessary intelligent control system, therefore installing the stall-regulated wind turbine in the low wind sites could be the attractive choice. Merely, by optimizing the aerodynamic efficiency of the rotor, the best wind turbine could produce the maximum annual yield for a given Weibull wind speed distribution.

Another important factor of designing the optimal rotor for the specific wind sites is the quality of the measured wind speeds. There are several parameters which have an effect on the quality of the measured wind speeds namely period of time for collecting wind data (weekly monthly or yearly), frequency of collecting data including the accuracy of the instruments, and so on. An acceptable wind data should be collected at least within 2 years [1]. Its frequency depends on the capability of the instrument which was collecting the data every minute. Afterwards the hourly mean wind speed was determined in order to reduce a large number of data and evaluate the statistical parameters.

The objectives of the present study are to maximize the annual energy (AEP) and to minimize the cost of energy (COE) produced by the optimal wind turbine. The iterative approach was utilized in order to complete the blade shape optimization by the aerodynamic model based on BEM theory.

According to this study focuses on a small wind turbine, therefore the initial cost of wind turbine would be evaluated from the cost of blade due to its weight.

\section{Study of Wind Statistic}

The measured wind speeds used in this study was acquired from 3 meteorological stations at Lamtakong in Nakhonratchasima, Khaokoh in Phetchaboon and Sirindhorn dam in Ubonratchathani. Lamtakong is located between $14^{\circ} 47^{\prime} 58 " \mathrm{~N}$ latitude and $101^{\circ} 33^{\prime} 32.2^{\prime \prime} \mathrm{E}$ longitude whereas Khaokoh is located between $16^{\circ} 37^{\prime} 56.69 " \mathrm{~N}$ latitude and $100^{\circ} 59^{\prime} 51.70 " \mathrm{E}$ longitude and Sirindhorn dam is located between $15^{\circ} 12^{\prime} 13.87^{\prime \prime N}$ latitude and $105^{\circ} 25^{\prime} 28.86^{\prime \prime} E$ longitude. All data was collected from 2006-2008 at the height of $661 \mathrm{~m}$ above sea level and has been supported by the Electricity Generating Authority of Thailand.

\subsection{The Real Wind Distribution}

The frequency distribution of the measured wind speeds is mostly presented as a wind speed histogram with a bin width of $1 \mathrm{~m} / \mathrm{s}$ [2]. It can be calculated from the Equation (1).

$$
f_{H}(v)=\frac{\sum_{i=1}^{n} A_{I_{k}}\left(V_{i}\right)}{n . W}, \quad v \in I_{k}
$$

where $n$ is the number of hourly mean wind speed data of the sample, $W$ is bin width and $A_{I_{k}}(u)$ is the indicator function of the interval $I_{k}$, which is 1 provided that $u \in I_{k}$ and is otherwise 0 . Each interval is equal to 1 according to the bin width setting. Figure 1 shows the frequency of the individual wind speed calculated from Equation (1).

\subsection{Weibull Distribution}

The measured frequency distribution is mostly fitted with the Weibull distribution function which is quite flexible due to its two parameters as shown in Equation (2)

$$
f(V)=\frac{k}{c}\left(\frac{V}{c}\right)^{k-1} \exp \left[-\left(\frac{V}{c}\right)^{k}\right]
$$

where $V$ is instantaneous wind speed, $k$ is shape parameter and $c$ is scale parameter $[\mathrm{m} / \mathrm{s}]$,

$$
k=\left(\frac{\sigma_{V}}{\bar{V}}\right)^{-1.086}, c=\frac{\bar{V}}{\Gamma(1+1 / k)}
$$

And $\bar{V}$ is mean wind speed can be calculated from following relation 


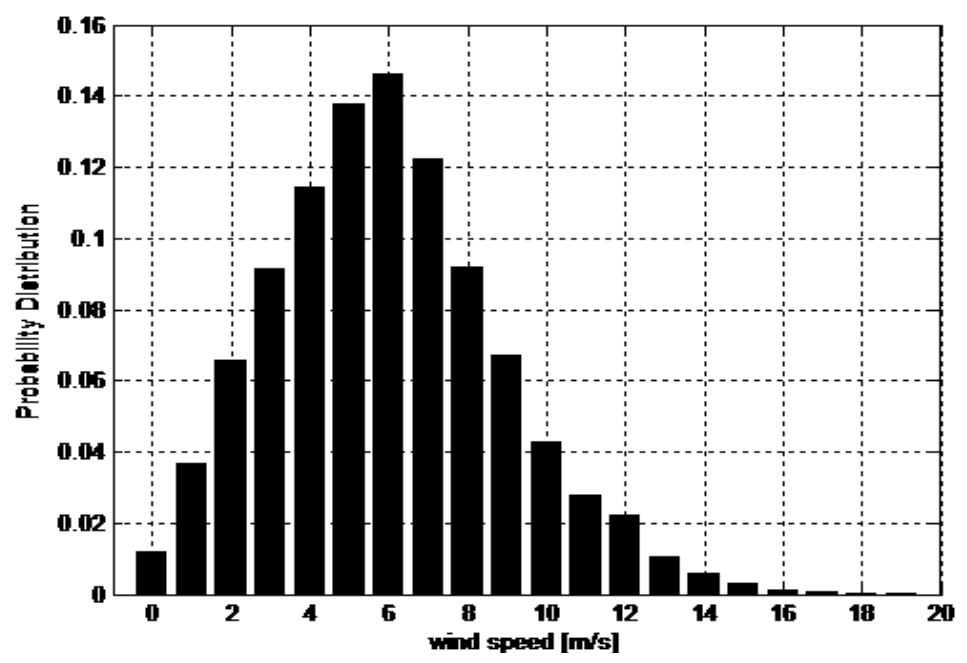

(a)

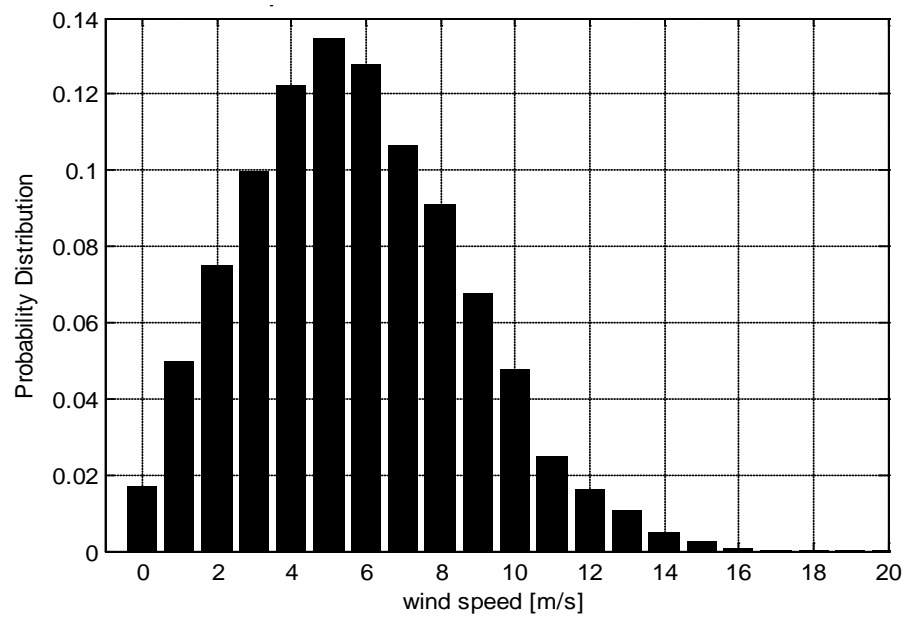

(b)

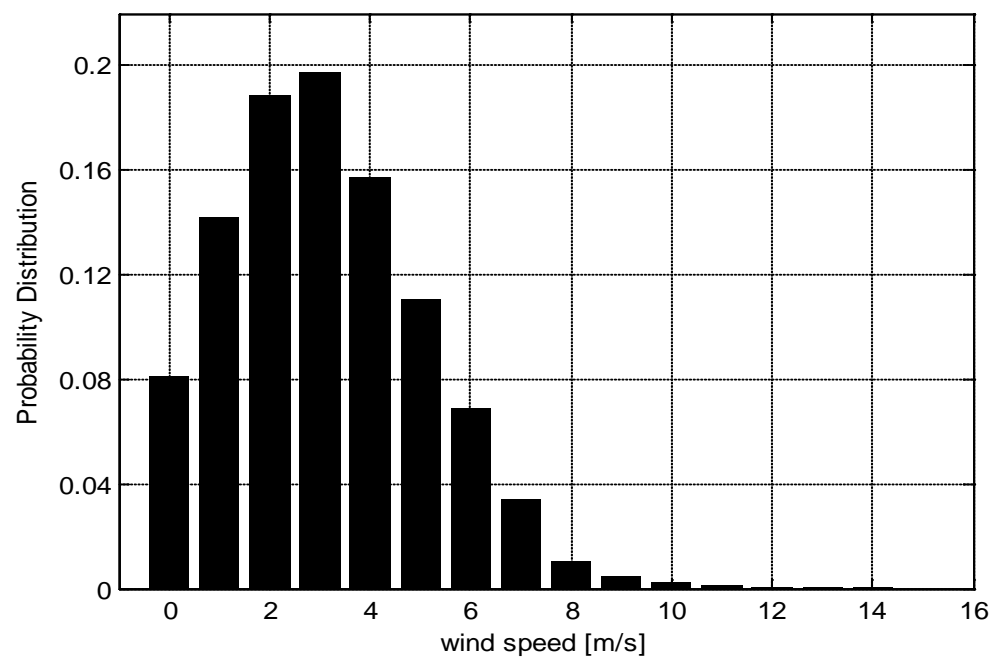

(c)

Figure 1. The measured wind speeds histogram. (a) at Lamtakong in Nakhonratchasima; (b) at Khaokoh in Phetchaboon; (c) at Sirindhorn dam in Ubonratchathani 


$$
\bar{V}=c \Gamma(1+1 / k), \Gamma(x)=\int_{0}^{\infty} e^{-t} t^{x-1} d t
$$

The Weibull distribution curve and statistical parameters corresponding to the measured wind speeds are expressed in Figure 2 and Table 1, respectively.

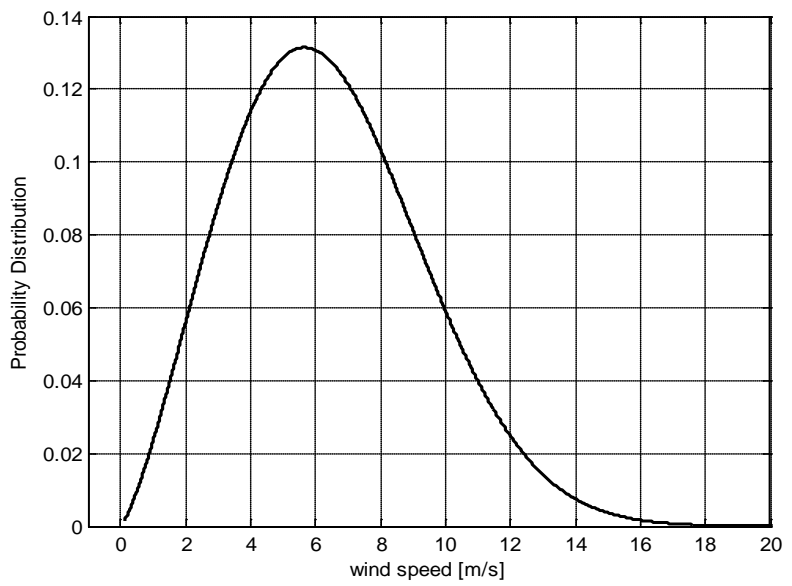

(a)

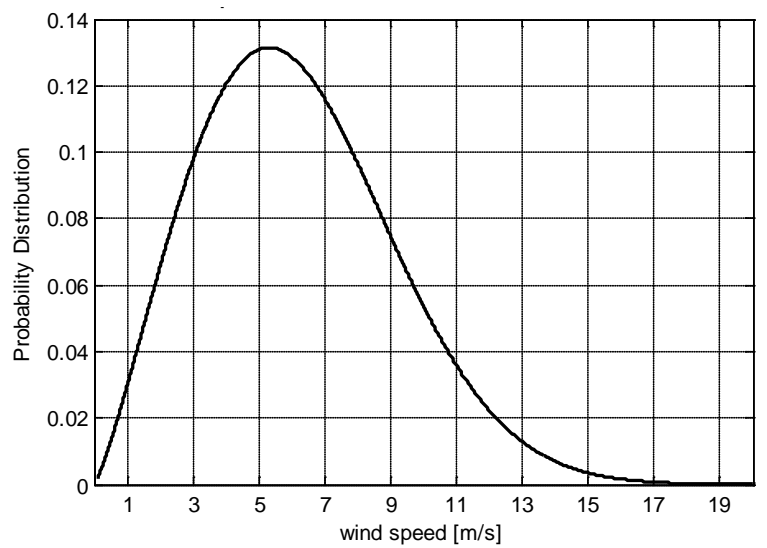

(b)

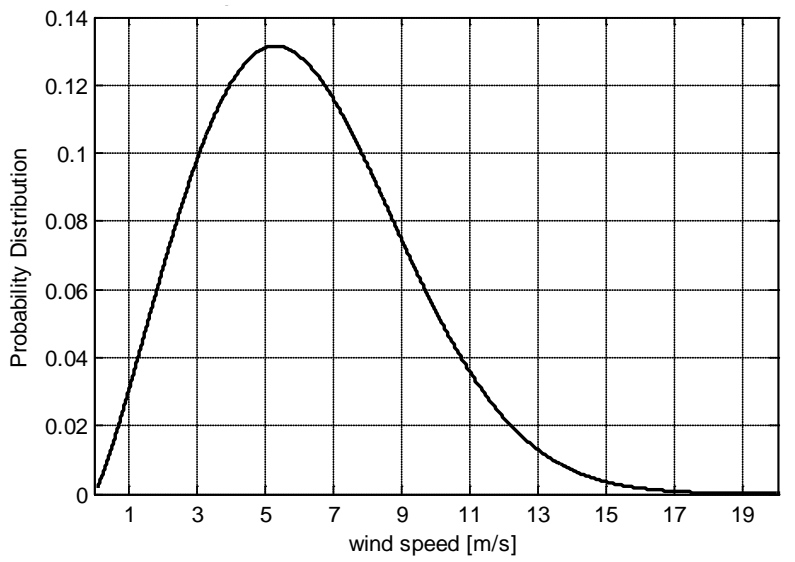

(c)

Figure 2. Weibull distribution curve. (a) at Lamtakong in Nakhonratchasima; (b) at Khaokoh in Phetchaboon; (c) at Sirindhorn dam in Ubonratchathani. 
Table 1. The statistical parameters at the three case study site.

\begin{tabular}{cccc}
\hline & Nakhonratchasima & Phetchaboon & Ubonratchathani \\
\hline $\mathrm{c}$ & $7.2427 \mathrm{~m} / \mathrm{s}$ & $6.9867 \mathrm{~m} / \mathrm{s}$ & $4.0096 \mathrm{~m} / \mathrm{s}$ \\
$\mathrm{k}$ & 2.3173 & 2.2089 & 1.8358 \\
Variance & 8.6374 & 8.7513 & 4.0475 \\
mean & $6.4170 \mathrm{~m} / \mathrm{s}$ & $6.1877 \mathrm{~m} / \mathrm{s}$ & $3.5625 \mathrm{~m} / \mathrm{s}$ \\
$\sqrt[3]{\left(V^{3}\right)}$ & $9.4700 \mathrm{~m} / \mathrm{s}$ & $9.3500 \mathrm{~m} / \mathrm{s}$ & $5.9900 \mathrm{~m} / \mathrm{s}$ \\
$\mathrm{R} 2$ & 0.9628 & 0.9511 & 0.8833
\end{tabular}

The $R^{2}$ considering between Weibull distribution function and the frequency distribution of the measured wind speeds can be calculated from Equation (3).

$$
R^{2}=1-\frac{\sum_{i=1}^{N}\left(p_{i}-\hat{p}_{i}\right)^{2}}{\sum_{i=1}^{N}\left(p_{i}-\bar{p}\right)^{2}}
$$

where $p_{i}$ is the relative frequency of the sample given by Equation (1), $\hat{p}_{i}$ is the probability obtained from Weibull function at each interval $I_{k}, \bar{p}$ is the mean of the total $p_{i}$ alues and $N$ is the total number of intervals.

In consequence, $R^{2}$ corresponding to the three case study sites namely Nakhonratchasima, Phetchaboon and Ubonratchathani are 0.9628, 0.9511 and 0.8833 , respectively. According to $R^{2}$ represents the credibility of Weibull distribution fitted by Weibull function and measured wind speeds, when it reaches to unity that means the Weibull distribution is good agreement with the frequency distribution of the measured wind speeds. Therefore, the Weibull distributions from the case studies were proper to predict the probability of the wind statistic in those sites.

\section{Aerodynamic Modeling}

BEM Theory is the most widely used method of calculating the preliminary performance of wind turbine due to its low computational demand and reasonable accuracy. This work will be carried out by the program "SuWiTStat" which based on BEM Theory in order to optimize a rotor performance by a given local wind statistic [3]. In this study, the wind speeds which produced the maximum wind power density, $\sqrt[3]{\left(V^{3}\right)}$, were chosen to be the design wind speeds as shown in Table 2.

The NREL Phase VI wind turbine with rated power of $19.8 \mathrm{~kW}$ was chosen to be the original model [4]. It has two twisted blades, a variable chord along the blade, and a rotor diameter of $10.1 \mathrm{~m}$. The aerodynamic crosssection is the S809 airfoil and is constant along the blades. The pitch angle is three degrees and rotational velocity is $72 \mathrm{rev} / \mathrm{min}$. Thereby the design parameters are chord, twist and pitch. The program was iteratively searching the optimal design parameters which provided the maximum power coefficient of each element calculated by Equation (4):

$$
C_{P, r}=d P_{r} / V_{d}^{3} \rho \pi r d r
$$

where

$$
d P_{r}=\frac{1}{2} \rho N V_{d}^{2} r C \Omega\left(C_{L} \sin \varphi_{r}-C_{D} \cos \varphi_{r}\right) d r
$$

\section{Optimization}

The design of the individual stall-regulated wind turbine, two objective functions were considered: maximum AEP and minimum COE. The AEP was calculated by Equation (6)

$$
A E P=8760 \int_{V} P_{t}(V) \times f(V) d V
$$


Table 2. AEP and COE of the optimized and the original wind turbine.

\begin{tabular}{ccc}
\hline \multirow{2}{*}{ Area } & \multicolumn{2}{c}{ AEO [MW.h/year] } \\
\cline { 2 - 3 } & Original & Smoothed \\
\hline Nakhonratchasima & 40.96 & 52.40 \\
Phetchaboon & 38.52 & 49.08 \\
Ubonratchathani & 12.51 & 14.06 \\
\hline
\end{tabular}

where $P_{t}$ was power of wind turbine produced at instantaneous wind speed.

The worthy of investment normally evaluated by COE which was calculated using the following equation [5]:

$$
C O E=\frac{T C+B O S}{A E P} \times F C R+O \& M
$$

In this equation, TC was the turbine cost (\$/kW.h) [6]. For the balance of station BOS varied with the machine rating $(\$ 200 / \mathrm{kW})$. The fixed charge rate FCR was $11 \% /$ year. The AEP was considering to be $98 \%$ availability. Finally, the operation and maintenance O\&M was fixed at $\$ 0.01 / \mathrm{kW} . \mathrm{h}$.

From Equation (7), TC depends on blade cost which was determined according to its weight. Assuming the blades were manufactured by E-glass using price of $\$ 20 / \mathrm{kg}$ where the blades represent $20 \%$ of the total turbine cost.

For evaluating the blades weight needed to know the skin thickness distribution along the blade. The skin thickness was determined according to the maximum allowable stress $\left(\sigma_{\max }\right)$ corresponding to the material strength of $110 \mathrm{MPa}$. If the residual stresses were taken into account, the $\sigma_{\max }$ equal to $94 \mathrm{MPa}$ was used.

The total stress acting on blade composed of two components, first tensile stress due to centrifugal force and stress due to bending moment, as shown in Equation (8):

$$
\sigma(r)=\frac{F_{r}(r)}{A(r)}+\frac{M(r)[t(r) / 2]}{I(r)}
$$

where $\sigma_{\max }=\chi \sigma(r)$ and a Safety margin $\chi$ equal to 10 . The cross-section was modeled as an I-beam without a shear web as shown in Figure 3. It represented the overall skin thickness that was subjecting the load.

The maximum stress acting on blade was calculated in the condition that wind turbine was parked and fully exposed to the storm. According to the International Electrotechnical Commission (IEC) [7], the IEC 50-year extreme wind speed for a wind Class II $(59.5 \mathrm{~m} / \mathrm{s})$ was used to compute the blade loads. In consequence, the minimum skin thickness, blade weight and blade cost as well as turbine cost were determined.

\section{Result and Discussion}

The optimal blade shapes for each case study are shown in Figures 4-6. In the optimization process, blade was divided into many elements so that the number of elements then brought about the discontinuity of the optimized points. However, increasing the number of elements made more reliable results but consumed more computational resource as well. Hence, the smoothed line was made for a feasibility of blade manufacturing. In addition, wind turbine with smoothed blades produced higher performances compared with the original one as shown in Figure 7 and Figure 8, particularly operating at the mean wind speeds of the studied sites.

Normally, the design of optimal blade was carried out using one design wind speed. Due to the fact that wind turbine was operating among fluctuated wind speed at a site. Thus, the pitch regulation was required to optimize the annual yield for a given wind statistic. As the results, the optimal wind turbines operated under the three cases of wind statistic in Nakhonratchasima, Phetchaboon and Ubonratchathani produced the AEP of 52.40, 49.08 and 14.06 MWh at pitch angle of $3^{\circ}, 2^{\circ}$ and $2^{\circ}$, respectively as shown in Figure 9. Whereas the original wind turbine produced the AEP of 40.96, 38.52 and 12.51 MWh which were decreased by 28.38\%, 35.08\% and 15.96\% compare with the optimized results. The results from Table 3 could be summarized that the COE evaluated from the optimal wind turbines could be reduced by 13.62\%, 10.67\% and 31.83\% compare with the original results.

As the results, the optimal wind turbine operated under the higher potential sites contributed the greater annual yield which leaded to the lower COE (Figure 10). However, the high profit margin does not only rely on a 


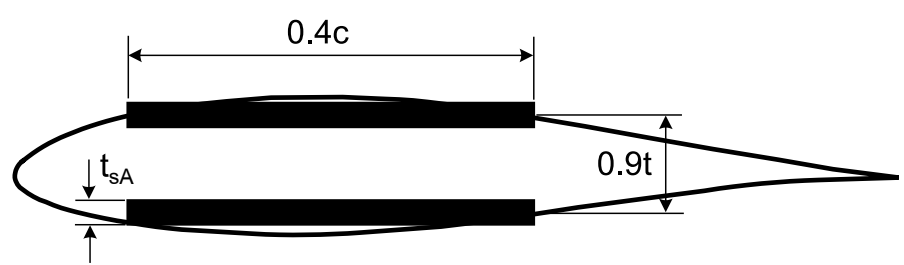

Figure 3. Model of the profile.

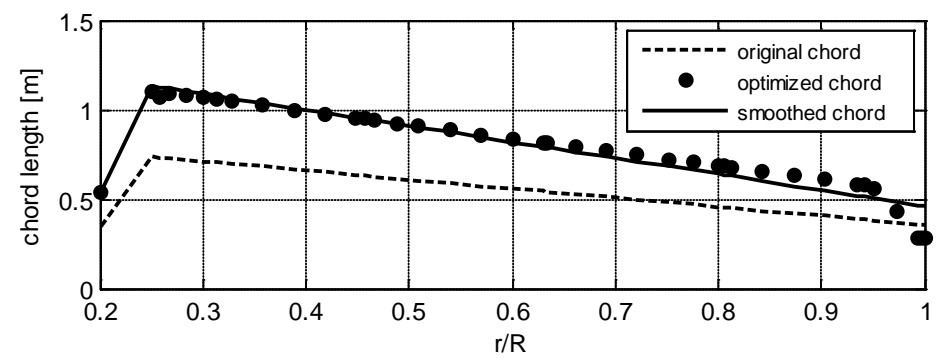

(a)

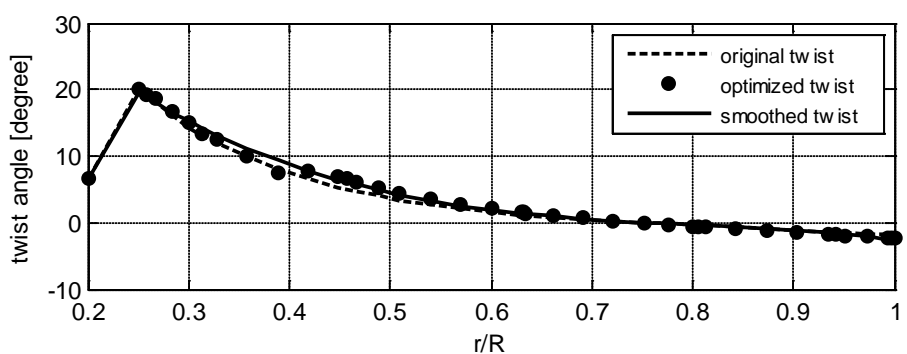

(b)

Figure 4. (a) Comparison of chord distribution; (b) Comparison of twist angle distribution (Nakhonratchasima).

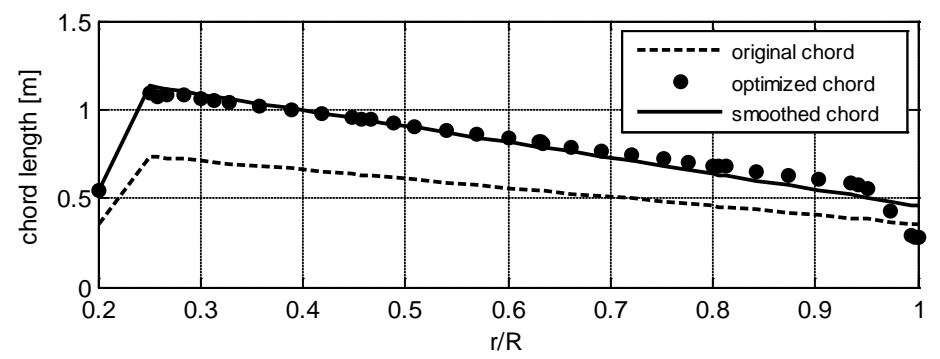

(a)

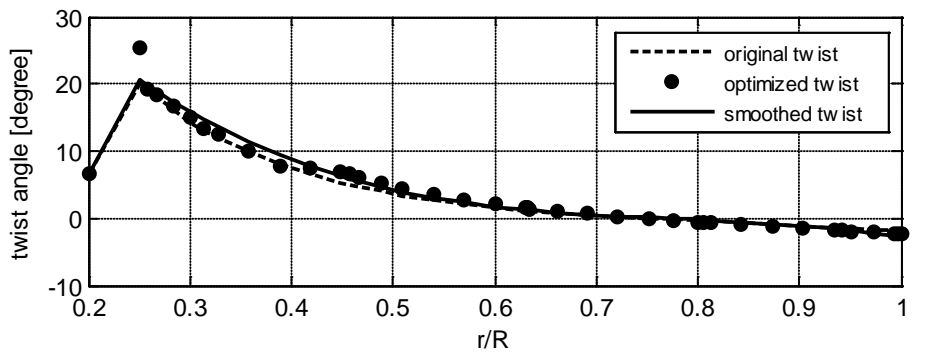

(b)

Figure 5. (a) Comparison of chord distribution (b) Comparison of twist angle distribution (Phetchaboon). 
Table 3. The optimal thickness and the minimum COE comparison between the optimized and the original wind turbine.

\begin{tabular}{cccc}
\hline Area & Optimal Thickness $[\mathrm{mm}]$ & \multicolumn{2}{c}{ COE $[\$ / \mathrm{kWh}]$} \\
\cline { 3 - 4 } & & Original & Smoothed \\
\hline Nakhonratchasima & 29.23 & 0.1909 & 0.1649 \\
Phetchaboon & 30.19 & 0.2025 & 0.1809 \\
Ubonratchathani & 24.38 & 0.6091 & 0.4152 \\
\hline
\end{tabular}

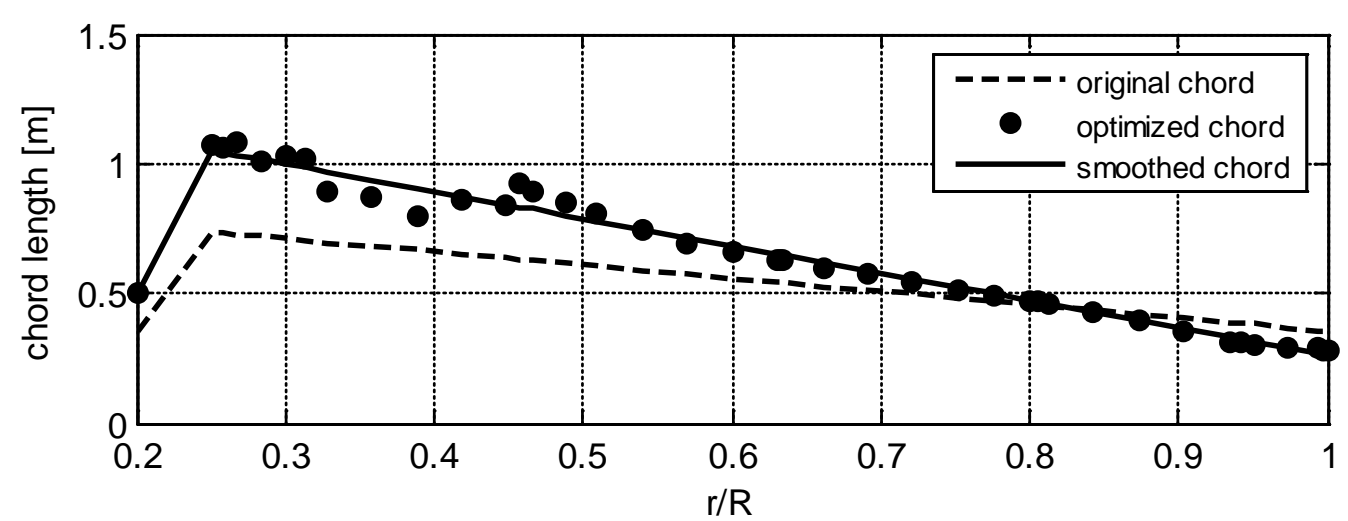

(a)

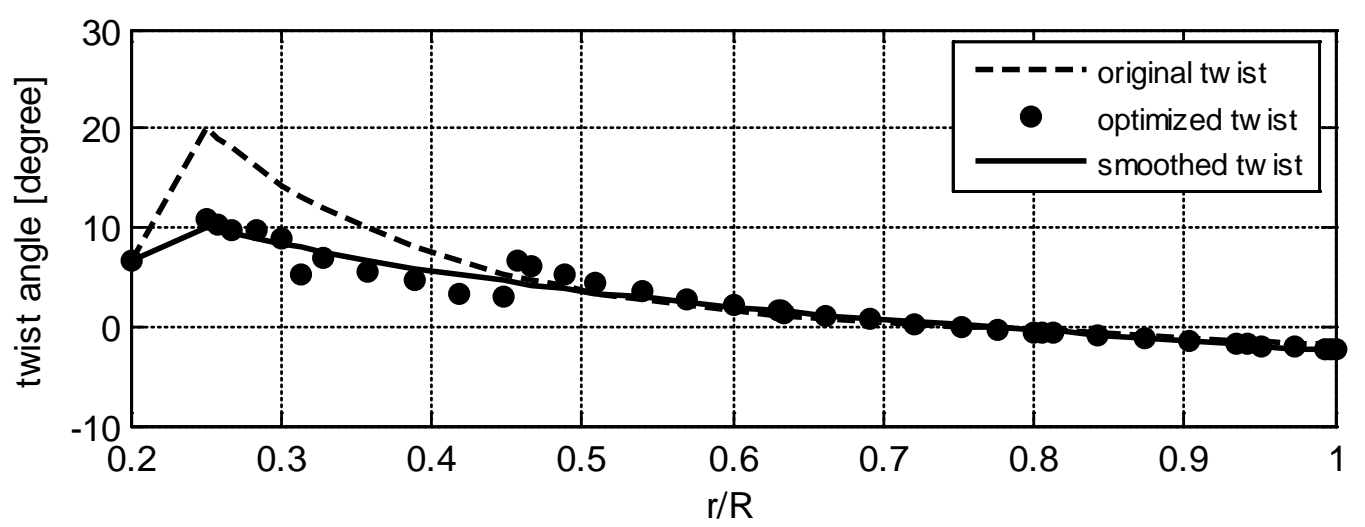

(b)

Figure 6. (a) Comparison of chord distribution (b) Comparison of twist angle distribution (Ubonratchathani).

minimum COE but concerns with a machine rating as well. What if the machine rating is increased, the higher electricity produced, the higher profitable revenue would be gained accordingly. This issue will be carried out in the further work.

\section{Conclusion}

The wind turbines imported from aboard were designed for the windy areas those were not working properly in the weak wind areas as in Thailand. Thus, optimizing wind turbine blades for domestic using could be the best solution for reducing the initial cost and enhancing the performance of wind turbine. As the results, the AEP produced by the wind turbines optimized with the local wind statistic in Nakhonratchasima, Phetchaboon and Ubonratchathani were increased by $28.38 \%$, 35.08\% and $15.96 \%$, respectively whereas the corresponding COE have been decreased by $13.62 \%, 10.67 \%$ and $31.83 \%$, respectively. For a long term consideration, it is worthy of installing these wind turbines because of the enormous profitable revenue from electricity selling correspond to the higher AEPs and the lower COEs can be achieved. 


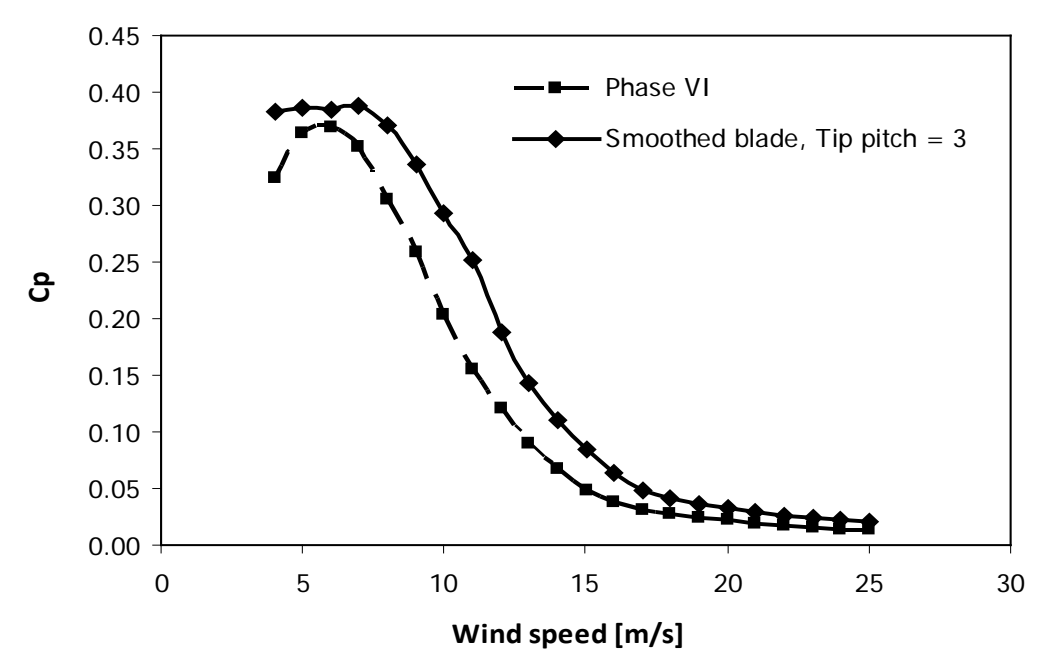

(a)

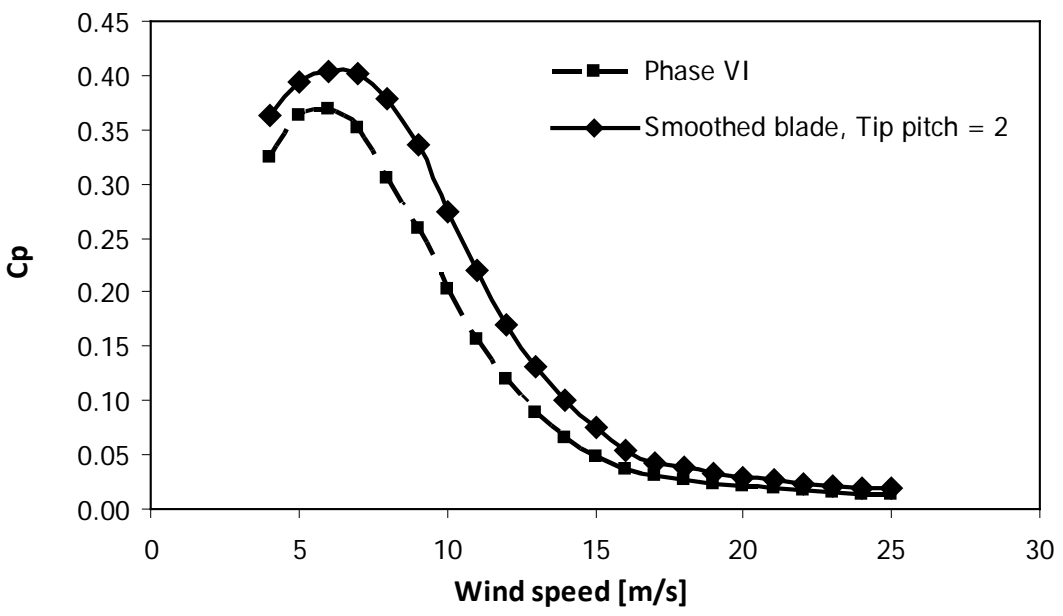

(b)

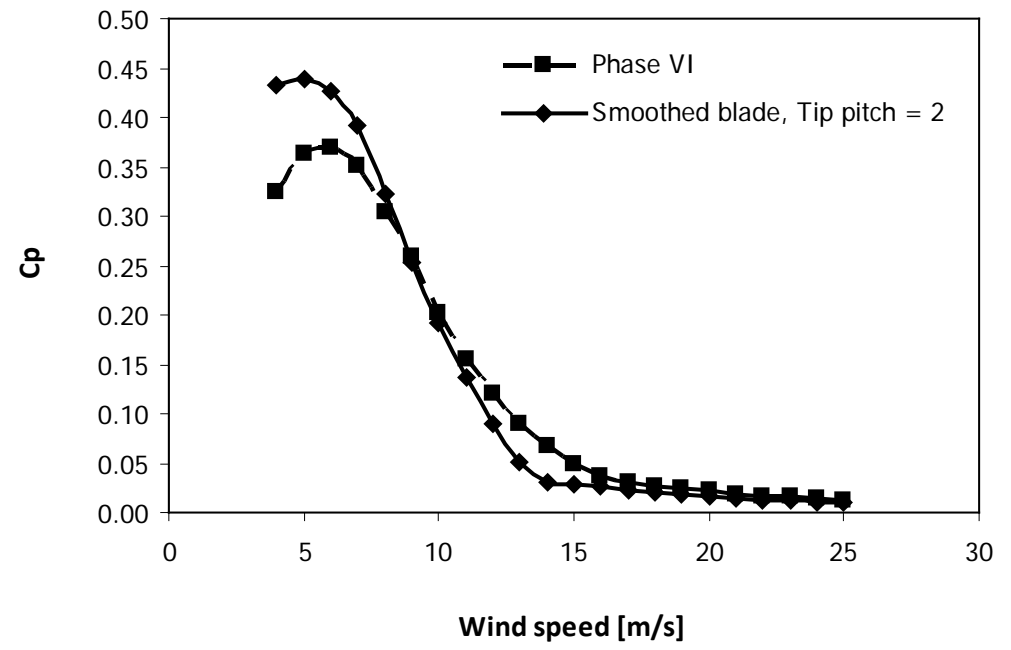

(c)

Figure 7. The power coefficient, comparison of between the optimized and the original wind turbine (a) Nakhonratchasima (b) Phetchaboon (c) Ubonratchathani. 


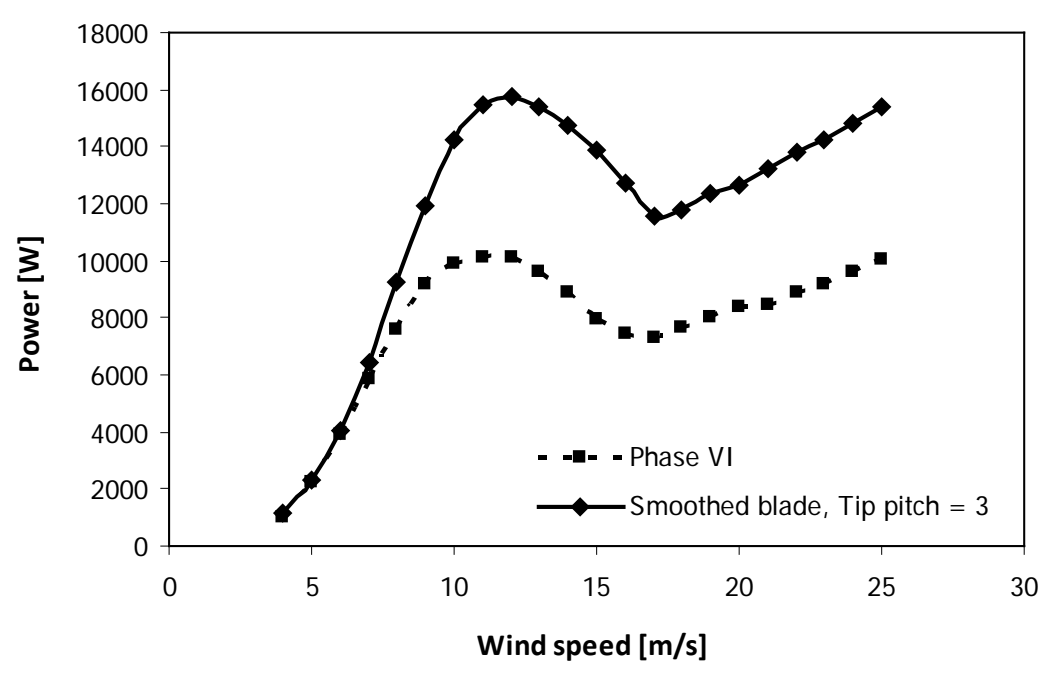

(a)

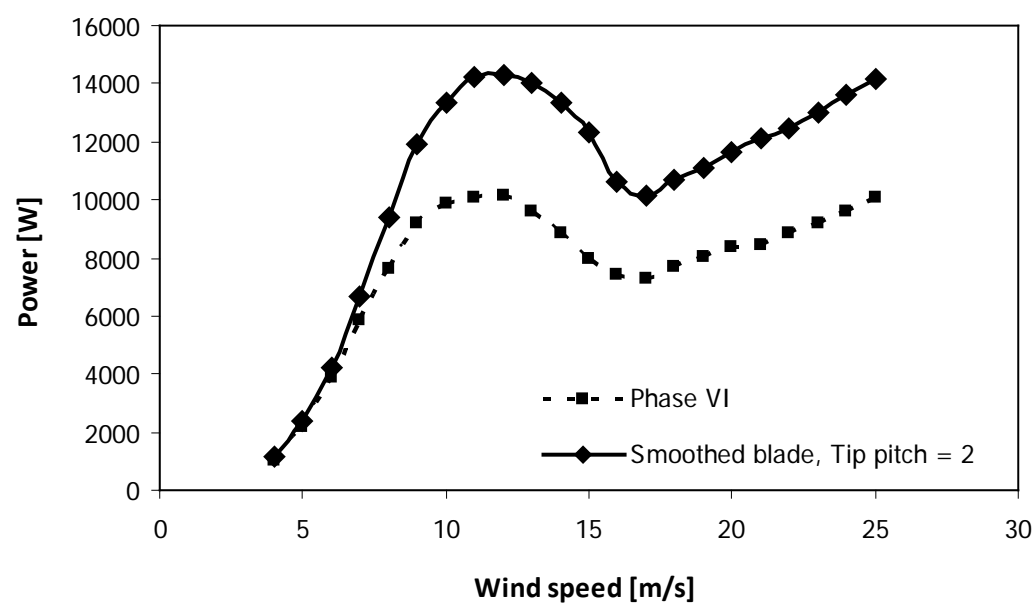

(b)

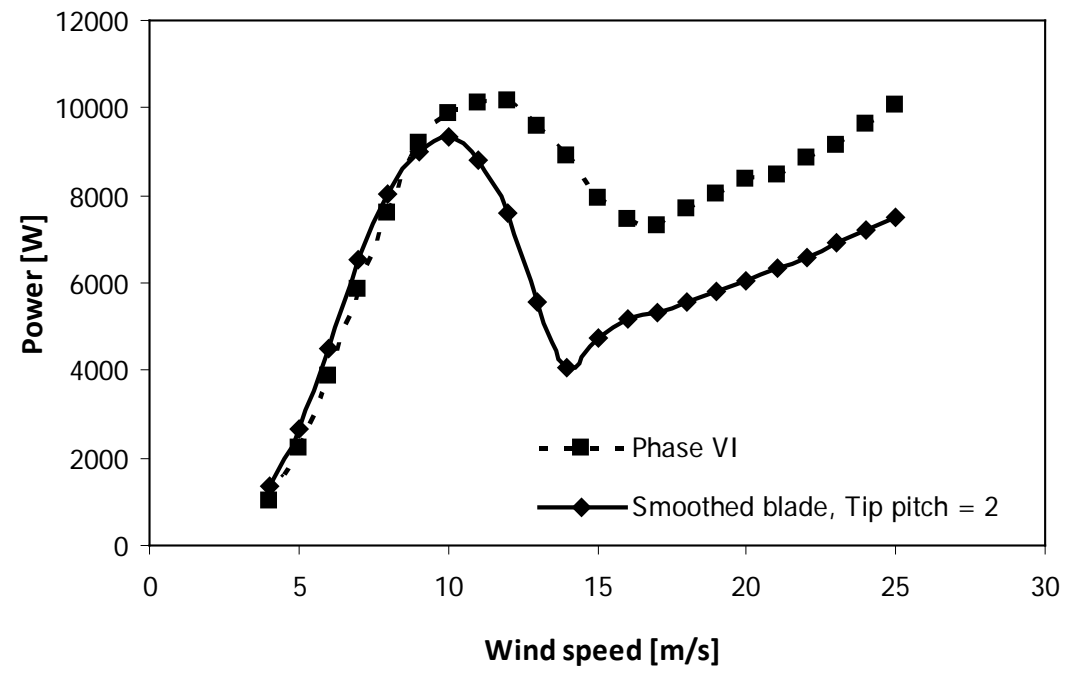

(c)

Figure 8. The power curve, comparison between the optimized and the original wind turbine (a) Nakhonratchasima (b) Phetchaboon (c) Ubonratchathani. 


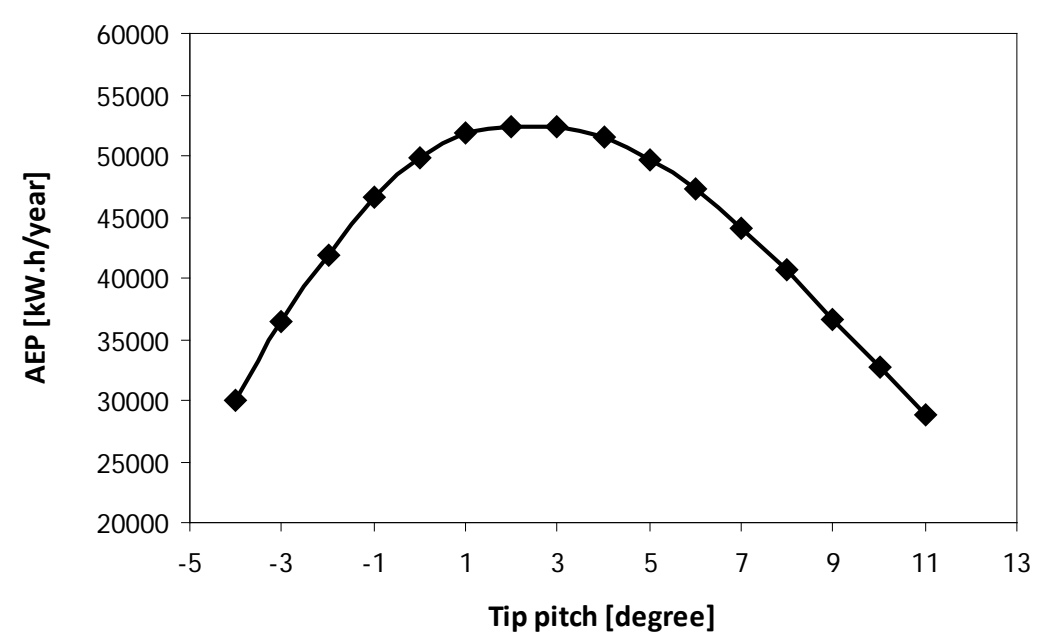

(a)

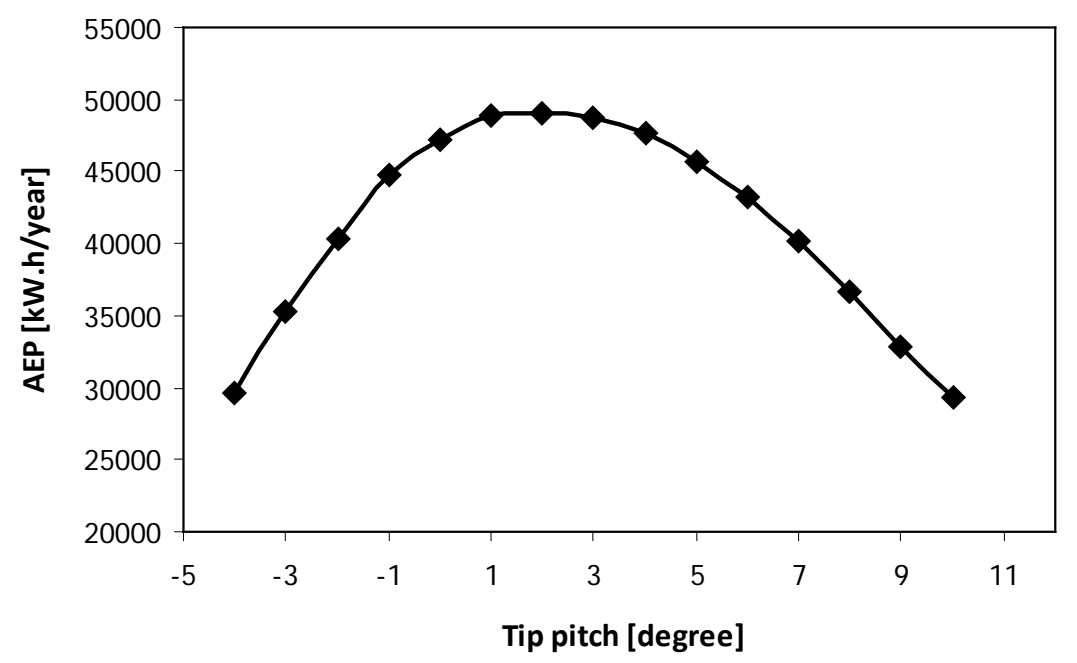

(b)

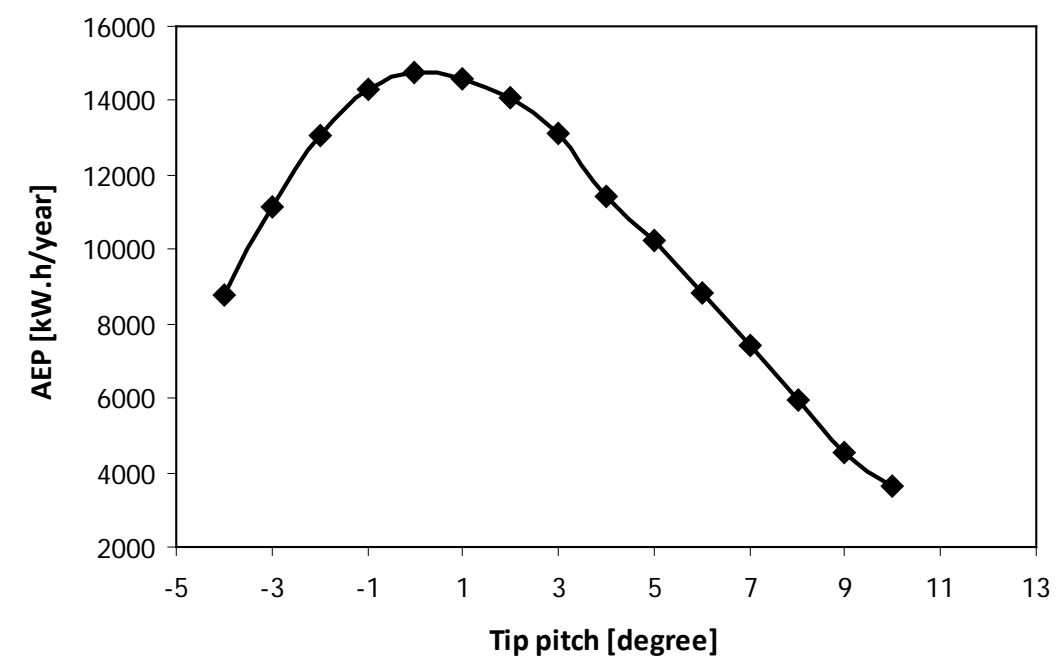

(c)

Figure 9. The variation of AEP with pitch angle (a) Nakhonratchasima (b) Phetchaboon (c) Ubonratchathani. 


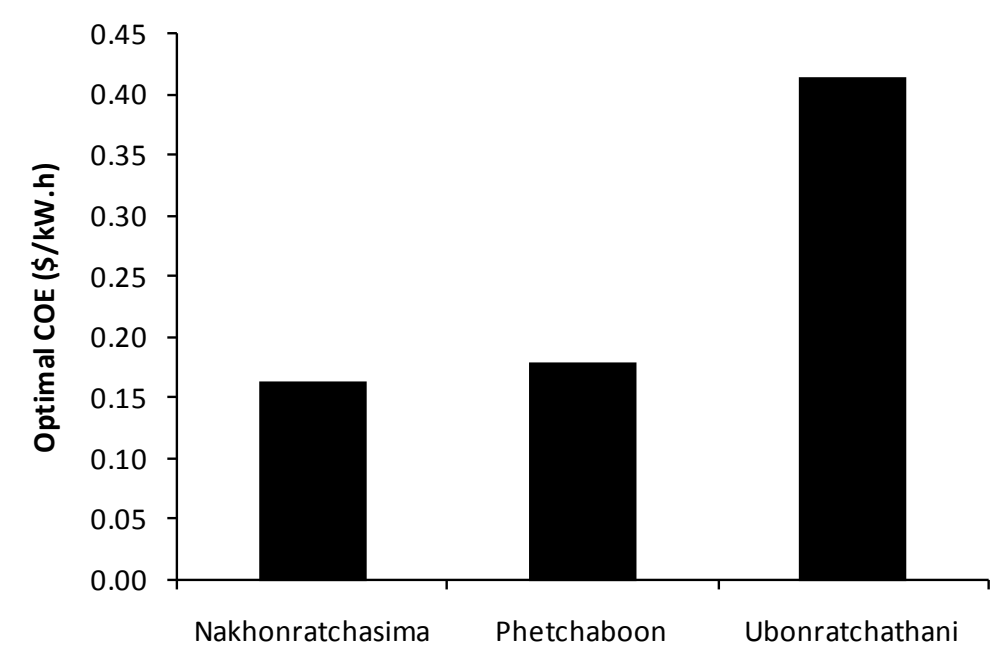

Figure 10. The optimal COE from the three case studies.

\section{Acknowledgements}

The authors would like to thank for the data used in this work that has been supported by the Electricity Generating Authority of Thailand.

\section{References}

[1] Spera, D.A. (1994) Wind Turbine Technology: Fundamental Concepts of Wind Turbine Engineering. ASME Press, New York.

[2] Cartar, J., Ramirez, P. and Velazquez, S. (2008) Influence of the Level of Fit of a Density Probability Function to Wind-Speed Data on the WECS Mean Power Output Estimation. Energy Conversion and Management, 49, 2647-2655. http://dx.doi.org/10.1016/j.enconman.2008.04.012

[3] Giguère, P., Selig, M.S. and Tangler, J.L. (1999) Blade Design Trade-Offs Using Low-Lift Airfoils for Stall-Regulated HAWTs. ASME/AIAA Wind Energy Symposium, Nevada, 11-14 January 1999.

[4] Sridech, W. and Chitsomboon, T. (2008) Optimal Stall-Regulated Wind Turbines in Unique Local Wind Statistic. The 22nd Conference of Mechanical Engineering Network of Thailand, Bangkok.

[5] Benini, E. and Toffolo, A. (2002) Optimal Design of Horizontal-Axis Wind Turbines Using Blade-Element Theory and Evolutionary Computation. Journal of Solar Energy Engineering, 124, 357. http://dx.doi.org/10.1115/1.1510868

[6] Humtae, C. and Chitsomboon, T. (2012) The Effect of Wind Speed and Wind Statistics Skewed on the Commercial Wind Turbine in Thailand. The 26th Conference of Mechanical Engineering Network of Thailand, Chengrai.

[7] International Electrotechnical Commission (1998) IEC 61400-1, Ed. 2: Wind Turbine Generator Systems-Part 1: Safety Requirements. FDIS 1998-12-15. 